\title{
Phytomedicine
}

Phytomedicine 15 (2008) 940-945

www.elsevier.de/phymed

\section{Essential oil from leaves of Cinnamomum osmophloeum acts as a xanthine oxidase inhibitor and reduces the serum uric acid levels in oxonate-induced mice}

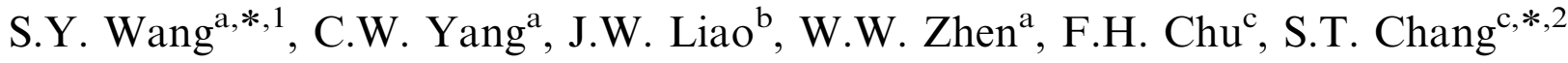 \\ ${ }^{a}$ Department of Forestry, National Chung-Hsing University, Taichung 402, Taiwan \\ ${ }^{\mathrm{b}}$ Graduate Institute of Veterinary Pathology, National Chung-Hsing University, Taichung 402, Taiwan \\ ${ }^{\mathrm{c}}$ School of Forestry and Resource Conservation, National Taiwan University, Taipei 106, Taiwan
}

\begin{abstract}
The xanthine oxidase (XOD) inhibitory activity and anti-hyperuricemia effect in mice of Cinnamomum osmophloeum, which is an endemic tree in Taiwan, were evaluated in this study. The results demonstrated that the essential oil of $C$. osmophloeum leaves presented the strongest XOD inhibition activity $\left(\mathrm{IC}_{50}=16.3 \mu \mathrm{g} / \mathrm{ml}\right)$; however, no significant XOD inhibition activities were found in ethanolic and hot water extracts. Furthermore, among the main compounds of essential oil, the cinnamaldehyde exhibited the potent XOD inhibition activity with an $\mathrm{IC}_{50}=8.4 \mu \mathrm{g} / \mathrm{ml}$. Besides, the reducing serum uric acid levels in oxonate-induced mice by cinnamaldehyde were further investigated. The hyperuricemic mice were oral administrated cinnamaldehyde at a dosage of $150 \mathrm{mg} / \mathrm{kg}$, the uric acid value in serum was reduced from $5.25 \pm 0.63$ to $2.10 \pm 0.04 \mathrm{mg} / \mathrm{dl}$, the levels of serum uric acid in mice was lowered down by $84.48 \%$ as compared to the hyperuricemic control group. Based on the results obtained in this study, cinnamaldehyde may be a potential lead compound for developing the pharmaceutic for anti-hyperuricemia agent.
\end{abstract}

(C) 2008 Elsevier GmbH. All rights reserved.

Keywords: Cinnamomum osmophloeum; Cinnamaldehyde; Hyperuricemia; Xanthine oxidase inhibitor; Hyperuricemia; Goat treatment

\section{Introduction}

The Lauraceae family, in the order Laurales, consists of more then 45 genera with around 2000-2500 species ( $\mathrm{Lu}$ et al., 2000). The genus Cinnamomum belongs to Lauraceae, which includes 250 species. Many plants of Cinnamomum have been applied as folk medicines for

\footnotetext{
*Corresponding author.

E-mail addresses: taiwanfir@dragon.nchu.edu.tw (S.Y. Wang), peter@ntu.edu.tw (S.T. Chang).

${ }^{1}$ Tel.: $+886422840345 \times 138$.

${ }^{2}$ Tel.: + 886233664626 .
}

their interesting bioactivities. Cinnamomum osmophloeum Kaneh. is an endemic tree of Taiwan. It grows in the natural hardwood forest at elevations between 400 and $1500 \mathrm{~m}$. The most impressive character for C. osmophloeum is that chemical compositions of its leaves essential oil are similar to those of the famous C. cassia (Cheng et al., 2004). Up to date, many biological activities of $C$. osmophloeum leaf essential oil have been confirmed, including anti-fungal activity (Wang et al., 2005; Cheng et al., 2006), anti-bacterial activity (Chang et al., 2001), anti-termitic activity (Chang and Cheng, 2002), anti-mite activity (Chen et al., 2002), mosquito larvicidal activity (Cheng et al., 
2004), antiinflammatory activity (Chao et al., 2005; Fang et al., 2006). As regards to the bark of $C$. cassia, it is a very famous traditional medicine and widely used in Asia country for a long time. The extracts from the bark of $C$. cassia have been claimed for antiinflammation (Lee et al., 2002), decreased serum glucose, total cholesterol and platelet counts (Khan et al., 2003). It was also proved to be active against HIV-1 and HIV-2 (Premanathan et al., 2000). Moreover, according to the results reported by Kong and his co-worker, the methanolic extract from the twig of $C$. cassia possessed the potent inhibitory activity for xanthine oxidase among 122 traditional Chinese medicinal plants, which were selected according to the clinical efficacy and prescription frequency for the treatment of gout and other hyperuricemia-related disorders (Kong et al., 2000). Recently, Zhao et al. (2006) demonstrated that cassia oil significantly reduced serum and hepatic urate levels in the hyperuricemia mice caused by oxonate.

Overproduction or underexcretion of uric acid leads to hyperuricemia, which is present in $5-30 \%$ of the general population and serum to be increasing global. Hyperuricemia has been considered an important risk factor for gout (Shimoto et al., 2005). Xanthine oxidase (XOD) catalyses the oxidation of hypoxanthine and xanthine to uric acid (Ramallo et al., 2006). XOD inhibitors could block the biosynthesis of uric acid from purine in the body, which should be one of the therapeutic approaches for treating hyperuricemia (Unno et al., 2004; Kong et al., 2002). As regards to XOD inhibitors, allopurinol is the most commonly used in the past decades (Field et al., 1996). However, a number of side effects caused accompanied with employed the allopurinol e.g. hepatitis, nephropathy, allergic reaction and 6-mercaptopurine toxicity (Kong et al., 2000, 2002). Therefore, there is an urgent need and trend to develop the new XOD inhibitors from natural source.

Although there are some evidence indicated that both of the methanolic extract of $C$. cassia and cassia oil exhibited XOD inhibition activity (Kong et al., 2000; Zhao et al., 2006), the exactly active components in the methanolic extract and/or C. cassia oil for inhibition the XOD activity and reducing serum urate levels in animal are not clear. On the other hand, since the chemical composition of essential oil from C. osmophloeum leaves is similar to those of $C$. cassia, it seems quite likely that the essential oil of $C$. osmophloeum may possess the XOD inhibition activity and reducing the serum uric acid in animal. In this study, the XOD inhibition activity of extracts from C. osmophloeum was evaluated. Furthermore, the chemical composition of active extracts was also characterized. Meanwhile, the principals of XOD inhibition and serum uric acid reducing effect in mice were also investigated.

\section{Material and methods}

\section{Plant material}

Leaves of C. osmophloeum were collected in June 2006 from the Da-Pin-Ting of Taiwan Sugar Farm located in Nantou County in central Taiwan. The species were identified by Prof. Y.-H., Tseng (Department of Forestry, National Chung-Hsing University), and voucher specimens were deposited at the Herbarium of Department of Forestry, National Chung-Hsing University.

\section{Extracts and essential oil preparation}

The extracts of $C$. osmophloeum were prepared by the following extractive procedures. A total of $100 \mathrm{~g}$ fresh leaves were extracted separately twice with $500 \mathrm{ml}$ of $70 \%$ ethanol at ambient temperature for 7 days. After combining two batches of extracts, the extract was concentrated to yield the ethanolic extract (EtOH-Ext). The hot water extract (HW-Ext) was obtained by refluxing $100 \mathrm{~g}$ fresh leaves with $500 \mathrm{ml}$ double distilled water for $2 \mathrm{~h}$ and then lyophilized into powder. On the other hand, fresh leaves $(200 \mathrm{~g})$ were subjected to hydrodistillation in a Clevenger-type apparatus for $6 \mathrm{~h}$, followed by determination of oil contents. Leaf essential oil (EO) was stored in airtight sample vial prior to analysis by gas chromatography-mass spectrometry (GC-MS) and bioactivity evaluation.

\section{GC-MS analyses}

A HP G1800A GC/MS instrument was used with a DB-5 column $(30 \mathrm{~m} \times 0.25 \mathrm{~mm}$ i.d., $0.25 \mu \mathrm{m}$ film thickness, J\&W scientific). The column temperature was held at $40{ }^{\circ} \mathrm{C}$ for $1 \mathrm{~min}$, then increased at $4{ }^{\circ} \mathrm{C} / \mathrm{min}$ to $260^{\circ} \mathrm{C}$ and held for $4 \mathrm{~min}$. The temperatures of injector and ion source (EI of $70 \mathrm{eV}$ ) were 250 and $260^{\circ} \mathrm{C}$, respectively. The carrier gas was $\mathrm{He}$ at a flow rate of $1 \mathrm{ml} / \mathrm{min}$, and the split ratio of 1:50 was performed. The MS scan range was $m / z$ 45-425. The Wiley GC-MS library (V. 7.00) was searched and authentic standards were used for compounds identification. The GC peak areas were used for quantification without individual response factors.

\section{In vitro inhibitory activity of $C$. osmophloeum extracts on xanthine oxidase}

The inhibitory effect on XOD was determined spectrophotometrically by following the increase in the absorbance at $295 \mathrm{~nm}$ (Kong et al., 2000). The reaction mixture consisted of $400 \mu \mathrm{l}$ of $200 \mathrm{mM}$ sodium pyrophosphate buffer (pH 7.5), $200 \mu 1$ of $0.6 \mathrm{mM}$ xanthine, $20 \mu \mathrm{l}$ of sample solution dissolved in distilled water or 
dimethylsulfoxide (DMSO), and $200 \mu$ xanthine oxidase $(0.1 \mathrm{U})$. DMSO was used for the samples not dissolvable in distilled water; the final concentration of DMSO in the assay was $1 \%$. The absorption increments at UV absorbance at $295 \mathrm{~nm}$ indicated the formation of uric acid. All determinations were performed in triplicate. For the EtOH-Ext, HW-Ext, and EO, the dosages for XOD inhibitory activity assays were examined at concentrations of $100,50,25,10,5,1 \mu \mathrm{g} / \mathrm{ml}$, respectively. On the other hand, the dosages for pure compounds and allopurinol assay were 100, 50, 25, 10, $5,3,2,1 \mu \mathrm{g} / \mathrm{ml}$. The inhibitory activity of XOD was assessed as inhibitory $(\%)=(1-b / a) \times 100$, where " $a$ " is the change in absorbance per min without the sample, and " $b$ " is the change in absorbance per min with the sample.

\section{Hypouricemic effects of cinnamaldehyde on potassium oxonate-induced hyperuricemia in mice}

Three-week-old male ICR mice (25-28g) were purchased from BioLASCO Co. (Taiwan) and each 10 mice in one group were housed in a plastic cage. Mice were allowed 1 week to adapt environment before test. They were housed in the conditions of temperature $\left(25 \pm 2{ }^{\circ} \mathrm{C}\right)$, relative humidity $(55 \pm 5 \%)$, lighting (06:00-18:00 h) with roden diet (LabDiet ${ }^{\circledR} 5001$ Rodent diet, Purina Mills LLC, ST. Lous, Mo, USA) and water ad libitum. The animals were transferred to the laboratory at least $1 \mathrm{~h}$ before the potassium oxonateinduced hyperuricemia experiment. Potassium oxonate (PO) is an uricase inhibitor (Stavric et al., 1995), which was used to induce hyperuricemia in ICR mice. The method used to examine the hupouricemic effects of cinnamaldehyde was followed by the methods reported previously (Zhao et al., 2006; Unno et al., 2004; Kong et al., 2002) with slight modifications. Briefly, the mice were divided into four groups $(n=10)$. Besides "normal group" (mice without treated with PO), the other three groups of mice, i.e. "PO", "PO + CA", and "PO + Allopurinol", were injected intraperitoneally with PO at a dosage of $250 \mathrm{mg} / \mathrm{kg} 1 \mathrm{~h}$ before drug administration to increase the serum urate level. After $1 \mathrm{~h}$, the mice in the "PO+CA" group were oral administrated $150 \mathrm{mg} / \mathrm{kg}$ cinnamaldehyde; in "PO + Allopurinol" group were oral administrated $10 \mathrm{mg} / \mathrm{kg}$ allopurinol; in "PO" group were administrated saline only. Two hours after PO-induced action, whole blood samples were collected from mice. The blood was allowed to clot for $1 \mathrm{~h}$ at ambient temperature and then centrifuged at $3000 \mathrm{rpm}$ for $5 \mathrm{~min}$ to obtain the serum. The serum was stored at $-20^{\circ} \mathrm{C}$ until assayed. The uric acid level was determined by the phosphotungstic acid method, as described elsewhere (Carroll et al., 1971).

\section{Statistical analysis}

Data are expressed as means \pm SE. Statistical comparisons of the results were made using analysis of variance (ANOVA). Significant differences $(* p<0.05$ and $* * p<0.01$ ) between the control (untreated) and treated cells were analyzed by Dunnett's test.

\section{Results and discussion}

\section{Yields and XOD inhibitory activity of extracts from C. osmophloeum leaves}

The yields of extracts from C. osmophloeum using different preparation methods were shown in Table 1 . The yields of ethanolic extracts (EtOH-Ext), hot water extracts (Hot-Ext), and hydrodistillation (EO) were $7.5 \pm 0.1 \%, 14.3 \pm 0.4 \%$, and $3.3 \pm 0.1 \%$, respectively. Extracts prepared by difference methods were further evaluated their XOD inhibitory activity in vitro. As shown in Table 1, the EtOH-Ext and Hot-Ext did not present XOD inhibitory activity, $\mathrm{IC}_{50}$ values for both of them were higher than $100 \mu \mathrm{g} / \mathrm{ml}$. However, the extract prepared from hydrodistillation, i.e. essential oil (EO), displayed a significant XOD inhibitory activity. When $\mathrm{IC}_{50}$ of allopurinol (commercial XOD inhibitor) was $0.6 \mu \mathrm{g} / \mathrm{ml}$, the $\mathrm{IC}_{50}$ for $\mathrm{EO}$ was $16.3 \pm 0.2 \mu \mathrm{g} / \mathrm{ml}$. Kong et al. (2000) had evaluated the XOD inhibitory activities of 122 traditional Chinese medicinal plants, which were selected according to the clinical efficacy and prescription frequency for the treatment of gout and other hyperuricemia-related disorder. Among 122 medicinal plants, the extract of $C$. cassia twig prepared by methanolic extraction possessed the strongest XOD inhibitory activity $\left(\mathrm{IC}_{50}=18 \mu \mathrm{g} / \mathrm{ml}\right)$, followed by the methanolic extract from Chrysanthemum indicum flower, the $\mathrm{IC}_{50}$ was $22 \mu \mathrm{g} / \mathrm{ml}$. Comparing with the extracts of $C$. cassia and $C$. indicum, the EO presented an excellent XOD inhibitory activity, suggesting that it may be a great potential to further investigate its hyperuricemia-reducing and/or even gout treatment effects.

Table 1. Yields and xanthine oxidase (XOD) inhibitory activity of extracts from C. osmophloeum leaves

\begin{tabular}{lrl}
\hline & Yield (\%) & $\begin{array}{l}\mathrm{IC}_{50} \text { of XOD inhibitory } \\
\text { activity }(\mu \mathrm{g} / \mathrm{ml})\end{array}$ \\
\hline EtOH-Ext & $7.5 \pm 0.1$ & $>100$ \\
Hot-Ext & $14.3 \pm 0.4$ & $>100$ \\
EO & $3.3 \pm 0.1$ & $16.3 \pm 0.2$ \\
Allopurinol $^{\mathrm{a}}$ & - & $0.6 \pm 0.0$ \\
\hline
\end{tabular}

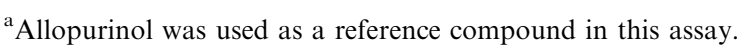


Table 2. Major components and relative contents of essential oil from C. osmophloeum leaves

\begin{tabular}{llcc}
\hline Peak no. & Compound & RT (min) & Content $(\%)$ \\
\hline 1 & $\alpha$-Pinene & 9.57 & 0.23 \\
2 & Camphene & 10.05 & 0.15 \\
3 & Benzaldehyde & 10.36 & 1.24 \\
4 & $\beta$-Pinene & 11.01 & 0.10 \\
5 & 3-Pheayl pionaldehyde & 17.87 & 1.29 \\
6 & cis-Cinnamaldehyde & 19.98 & 0.89 \\
7 & trans-Cinnamaldehyde & 21.86 & 74.16 \\
8 & Isobornyl acetate & 22.05 & 0.52 \\
9 & Eugenol & 24.67 & 0.81 \\
10 & Cinnamyl acetate & 27.43 & 20.61 \\
\hline
\end{tabular}

RT: retention time.

\section{Chemical composition analysis of essential oil}

Since EO revealed a significant XOD inhibitory activity, the composition of EO was analyzed by using the GC-MS technique, the result is shown in Table 2. The main component of EO was cinnamaldehyde (76.16\%), followed by cinnamyl acetate $(20.61 \%)$, and the contents of the other constituents were less than $2 \%$. According to the classification of $\mathrm{Hu}$ et al. (1985), the tree used in this study was belonging to cinnamaldehyde type of $C$. osmophloeum. From the chemical composition point of view, $C$. osmophloeum is a unique tree species. The constituents in $C$. osmophloeum leaf essential oil are similar to those of famous $C$. cassia. However, the active compound, e.g. cinnamaldehyde, is richly distributed in the leaves, not in the bark or twig. From forestry conservation point of view, to utilize the leaves of tree without fall it down is the best way for application the natural resource.

\section{XOD inhibitory activity of main components in EO}

Based on the results obtained by GC-MS analysis, the compositions of EO were cinnamaldehyde $(74.16 \%)$, cinnamyl acetate $(20.61 \%)$, 3-pheayl pinoaldehyde $(1.29 \%)$, benzaldehyde $(1.24 \%)$, eugenol $(0.81 \%)$, isobornyl acetate $(0.52 \%), \alpha$-pinene $(0.23 \%)$, camphene $(0.15 \%), \quad \beta$-pinene $(0.10 \%)$ (Table 2). The XOD inhibitory activities of major compounds of EO were further evaluated in this study. Fig. 1 demonstrates the $\mathrm{IC}_{50}$ values of compounds from C. osmophloeum leaves against XOD activity. It is obvious that cinnalmaldehyde presented the strongest XOD inhibitory activity $\left(\mathrm{IC}_{50}=8.4 \mu \mathrm{g} / \mathrm{ml}\right)$. The $\mathrm{IC}_{50}$ value of allopiurinol, being clinically used as a XOD inhibitory drug, was $0.6 \mu \mathrm{g} / \mathrm{ml}$. Although benzaldehyde possessed a slight XOD inhibitory activity $\left(\mathrm{IC}_{50}=27.0 \mu \mathrm{g} / \mathrm{ml}\right)$, the amount of benzaldehyde was only $1.24 \%$. Besides, the $\mathrm{IC}_{50}$ values for other compounds were higher than $100 \mu \mathrm{g} / \mathrm{ml}$. We

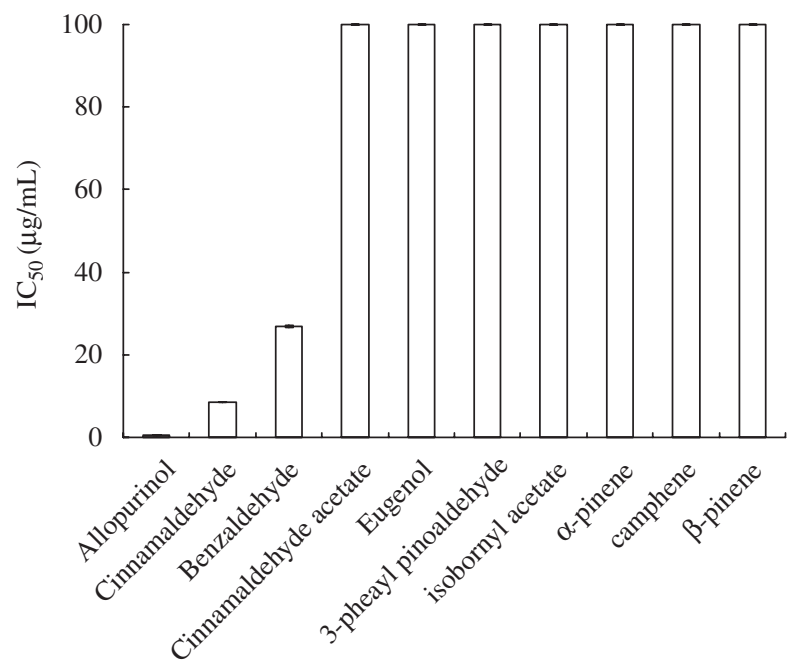

Fig. 1. $\mathrm{IC}_{50}$ values of components of $C$. osmophloeum leaves and allopurinol against xanthine oxidase. The data are representative of three experiments and expressed as mean \pm S.E.

concluded that cinnamaldehyde contributes the most of XOD inhibitory activity in EO. Recently, the XOD inhibitory activity of cassia oil had been reported (Zhao et al., 2006). However, the bioactivity principal contributed the XOD inhibitory activity of cassia oil has not been reported until now. According to the results presented in this study, it was approved that cinnamaldehyde is the principal component for XOD inhibitory activity both in cassia oil and/or EO of C. osmophloeum.

\section{Effects of cinnamaldehyde and allopurinol on serum urate levels in hyperuricemic mice induced by potassium oxonate}

As the results presented above, cinnamaldehyde exhibited a potent XOD inhibitory activity, the serum uric acid reducing effect by cinnamaldehyde in oxonateinduced mice by cinnamaldehyde was further investigated. The serum level of uric acid in mice was induced by uricase inhibitor potassium oxonate (PO). As shown in Fig. 2, initial serum uric acid level in mice was $1.73 \pm 0.27 \mathrm{mg} / \mathrm{dl}$. After intraperitoneal injection of PO caused a significant increase of serum uric acid level in PO-treated mice, the level of uric acid was reached at $5.25 \pm 0.63 \mathrm{mg} / \mathrm{dl}$ after injection of PO for $3 \mathrm{~h}$ later. The hypouricemic effects of cinnamaldehyde and allopurinol on the serum uric acid levels in hyperuricemic mice are shown in Fig. 2. After a single oral administration of cinnamaldehyde at a dosage of $150 \mathrm{mg} / \mathrm{kg}$ in hyperuricemic mice, the serum uric acid value was reduced to $2.10 \pm 0.04 \mathrm{mg} / \mathrm{dl}$, the serum uric and levels of mice was lowered down by $84.48 \%$ as compared to the hyperuricemic control group. In the same treatment, allopurinol at a dosage of $10 \mathrm{mg} / \mathrm{kg}$, the serum uric acid of mice was 


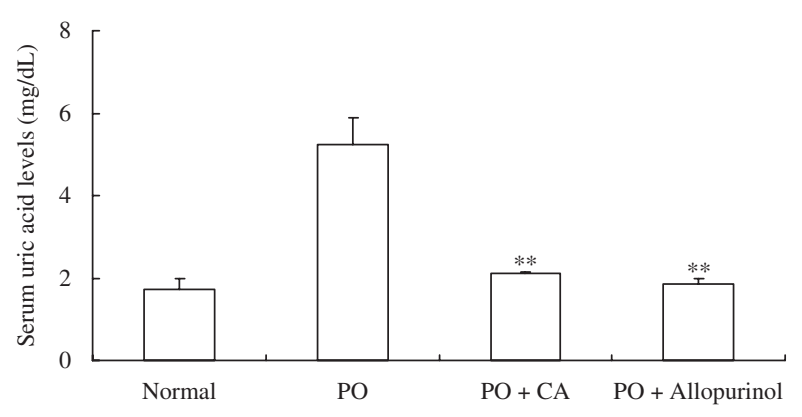

Fig. 2. Effects of cinnamaldehyde and allopurinol on urate levels in serum and liver in the hyperuricemic mice pretreated with potassium oxonate (PO). Normal: mice without treated with PO; PO: mice treated with $\mathrm{PO}$; $\mathrm{PO}+\mathrm{CA}$ : mice administrated $150 \mathrm{mg} / \mathrm{kg}$ cinnamaldehyde after treated with $\mathrm{PO}$; $\mathrm{PO}+$ allopurinol: mice administrated $10 \mathrm{mg} / \mathrm{kg}$ allopurinol after treated with PO. The data are representative of 10 animals and expressed as mean \pm S.E. ${ }^{* *} p<0.01$ compared with PO controls.

reduced to $1.84 \pm 0.13 \mathrm{mg} / \mathrm{dl}$. Zhao et al. (2006) have investigated hypouricemic effects of cassia oil from C. cassia by using the similar animal model, and the cassia oil demonstrated a good inhibitory activity for reducing the XOD activity. Administration of cassia oil significantly reduced the serum uric acid level in hyperuricemic mice at a dosage of $450 \mathrm{mg} / \mathrm{kg}$ of cassia oil or above. There are not different from the normal control mice, cassia oil at $600 \mathrm{mg} / \mathrm{dl}$ was found to be as potent as allpurinol. In this study, we further proved that cinnamaldehyde is a strong XOD activity inhibitor and presented the strong uric acid reducing effect in PO-induced mice. No matter cassia oil or cinnamaldehyde are common fragrance additives in foods, various food supplements, and cosmetic products, even used in many formulas of traditional herb medicines. In addition to the many biological activities of cinnamaldehyde have been reported previously, it is suggested that cinnamaldehyde may be a potent uric acid lowering agent. Although there are some safety concerns about high intake of cinnamon powders due to the coumarin existed in it, the formulae used in this study are essential oil and cinnamaldehyde. According to the report from US Department of Health and Human Services (NTP TR 514, 2004), oral administration of cinnamaldehyde for long-term period ( 3 months to 2 years) is safe for rats and mice even at $5475 \mathrm{mg} / \mathrm{kg}$. The highest dosage for cinnamaldehyde used in this study is $150 \mathrm{mg} / \mathrm{kg}$. Thus, it may have a great potential to develop it as an anti-hyperuricemia agent for clinical application.

\section{Acknowledgements}

This study was supported by a grant (96AS-7.2.2-FBe2) from the Council of Agriculture (COA) of Executive
Yuan, Taiwan. The authors thank COA for the financial support.

\section{References}

Carroll, J.J., Roberta Douglass, H.C., Badson, A.L., 1971. A simplified alkaline phosphotungstate assay for uric acid in serum. Clin. Chem. 17, 158-160.

Chao, L.K., Hua, K.F., Hsu, H.Y., Cheng, S.S., Lin, J.Y., Chang, S.T., 2005. Study on the anti-inflammatory activity of essential oil from leaves of Cinnamomum osmophloeum. J. Agric. Food Chem. 53, 7274-7278.

Chen, P.F., Chang, S.T., Wu, H.H., 2002. Antimite activity of essential oils and their components from Cinnamomum osmophloeum. Q. J. Chin. For. 35, 397-404.

Chang, S.T., Cheng, S.S., 2002. Antitermitic activity of leaf essential oils and components from Cinnamomum osmophloeum. J. Agric. Food Chem. 50, 1389-1392.

Chang, S.T., Chen, P.F., Chang, S.C., 2001. Antibacterial activity of leaf essential oils and their constituents from Cinnamomum osmophloeum. J. Ethnopharmacol. 77, 123-127.

Cheng, S.S., Lin, J.Y., Tsai, K.H., Chen, W.J., Chang, S.T., 2004. Chemical composition and mosquito larvicidal activity of essential oils from leaves of different Cinnamomum osmophloeum provenances. J. Agric. Food Chem. 52, 4395-4400.

Cheng, S.S., Lin, J.Y., Hsui, Y.R., Chang, S.T., 2006. Chemical polymorphism and antifungal activity of essential oils from leaves of different provenances of indigenous cinnamon (Cinnamomum osmophloeum). Bioresour. Technol. 97, 306-312.

Fang, S.H., Rao, Y.K., Tzeng, Y.M., 2006. Inhibitory effects of flavonaol glycosides from Cinnamomum osmophloeum on inflammatory mediators in LPS/IFN- $\gamma^{-}$activated murine macrophages. Bioorg. Med. Chem. 13, 2381-2388.

Field, M., Lewis, C.G., Lura, M.D., 1996. Allopurinol, an inhibitor of xanthine oxdiase, reduces uric acid levels and modifies the signs associated with copper deficiency in rats fed fructose. Free Radical Biol. Med. 20, 595-600.

Hu, T.W., Lin, Y.T., Ho, C.K., 1985. Natural variation of chemical components of the leaf oil of Cinnamomum osmophloeum Kaneh. Bulletin of Taiwan Forestry Research Industry New Series, p. 78.

Khan, A., Safdar, M., Ali Khan, M.M., Khattak, K.N., Anderson, R.A., 2003. Cinnamon improves glucose and lipids of people with type 2 diabetes. Diabetes Care 26, 3215-3218.

Kong, L., Zhou, J., Wen, Y., Li, J., Cheng, C.H.K., 2002. Aesculin processes potent hypouricemic action in rodents but in deviod of xanthine oxidase/dehydrogenase inhibitory activity. Planta Med. 68, 175-178.

Kong, L.D., Cai, Y., Huang, W.W., Cheng, C.H.H., Tan, R.X., 2000. Inhibition of xanthine oxidase by some Chinese medicinal plants used to treat gout. J. Ethnophar. 73, 199-207.

Lee, H.S., Kim, B.S., Kim, M.K., 2002. Suppression effect of Cinnamomum cassia bark-derived component on nitric oxide synthase. J. Agric. Food Chem. 50, 7700-7703. 
Lu, F.Y., Ou, C.H., Chen, Y.C., Chi, Y.S., Lu, K.C., 2000. Tree of Taiwan I. National Chung-Hsing University Press, Taichung, Taiwan.

Premanathan, M., Rajendran, S., Ramanathan, T., Kathiresan, K., Nakashima, H., Yamamoto, N., 2000. A survey of some Indian medicinal plants for anti-human immunodeficiency virus (HIV) activity. Indian J. Med. Res. 112, 73-77.

Ramallo, I.A., Zacchino, S.A., Furlan, R.L.E., 2006. A rapid TLC autographic method for the detection of xanthine oxidase inhibitors and superoxide scavengers. Phytochem. Anal. 17, 15-19.

Shimoto, T., Ashizawa, N., Matzumoto, K., Nakazawa, T., Nagata, O., 2005. Simultaneous treatment with citrate prevents nephropathy induced by FYX-051, a xanthine oxidoreductase inhibitor, in rats. Toxicolog. Sci. 87, 267.
Stavric, B., Clayman, S., Grodd, R.E.A., Hebert, D., 1995. Some in vivo effects in the rat induced by chloprothixene and potassium oxonate. Pharmaco. Res. Commun. 7, 117-124.

Unno, T., Sugimoto, A., Kakuda, T., 2004. Xanthine oxidase inhibitors from the leaves of Lagerstroemia speciosa (L). Pers. J. Ethnopharmacol. 93, 391-395.

Wang, S.Y., Chen, P.F., Chang, S.T., 2005. Antifurgal activities of essential oils and their constituents from indigenous cinnamon (Cinnamomum osmophloeum) leaves against wood decay fungi. Bioresour. Technol. 96, 813-818.

Zhao, X., Zhu, J.X., Mo, S.F., Pan, Y., Kong, L.D., 2006. Effect of cassia oils on serum and hepatic uric acid levels in oxonate-induced mice and xanthine dehydrogenase and xanthine oxidase activities in mouse liver. J. Ethnophare. 103, 357-365. 